\title{
PARA UMA FENOMENOLOGIA DA ALMA FEMININA: O PROTAGONISMO E A VISIBILIDADE DA MULHER NA AMAZÔNIA
}

\section{Adson Manoel Bulhões da Silva Iraildes Caldas Torres}

\begin{abstract}
A força criadora escorre pelo terreno da nossa psique à procura de depressões naturais, os arroyos, os canais que existem em nós. Nós nos tornamos seus afluentes e sua bacia. Somos as suas piscinas naturais, suas represas, córregos e santuários. A força criadora selvagem escorre para todos os leitos de que dispomos, aqueles que nascemos bem como aqueles que escavamos com as nossas próprias mãos. Clarissa PinkolaEstés
\end{abstract}

\section{Introdução}

O tema da alma feminina é discutido neste trabalho na perspectiva de gênero sob uma abordagem fenomenológica. Iniciamos essa discussão pondo em relevo os efeitos de uma luminosidade epistêmica e a necessidade de se examinar determinados temas que foram postos à sombra do conhecimento ao longo dos processos históricos, como é o caso dos estudos sobre a mulher e a condição feminina.

Historicamente, as mulheres estiveram associadas à terra no sentido simbólico da procriação, assumindo um significado de menor importância frente aos temas de construção de conhecimento. Deve-se perceber que essa visão excludente que vê a mulher e a natureza como objeto inferiorizado legitima o pensamento androcêntrico que estabelece o binarismo entre homem e mulher e consequentemente entre humanos e natureza.

A perspectiva do sagrado feminino que sempre foi preterido pela ciência pode constituir-se numa chave de leitura fundamental para explicar a feminização da natureza, especialmente a terra, que possui um substrato simbólico vital de relações com as mulheres. Logo, o feminino é um valor ontológico, um princípio relacional e colaborativo que reforça a capacidade de criar, incluir, acolher e cuidar, presente em homens e mulheres. Dessa forma, falar de uma natureza feminina supõe um olhar para além da cultura ocidentarizada. 
Com base nisso, faz-se necessário voltar às coisas primeiras e à ancestralidade da própria ideia e noção de natureza, que assinalam o imaginário dos povos; os saberes tradicionais constituídos pela cosmovisão dos povos originários, incluindo sua teogonia e todo o seu acervo mitológico, que estruturam seus modos de vida, podem constituir-se num debate candente explicativo do sagrado feminino que subjaz à alma feminina.

Este texto traz as discussões da alma feminina em conectividade com o eterno feminino, a partir de um cotejamento de dados retirados dos escritos de Edith Stein, em dialágo com teorias de gênero e com os saberes mitológicos. Portanto, esperamos poder contribuir para com a temática de gênero na Amazônia, sobretudo no que diz respeito à visão de Stein sobre a mulher, a natureza e o eterno feminino.

\section{O semblante feminino da natureza}

A dimensão do feminino é um tema que se encontra inserido nos estudos dedicados a formação humana e alicerçado na vertente fenomenológica por meio das contribuições de Edith Stein, filósofa e representante do pensamento de Edmund Husserl (1859-1938). Stein desenvolveu seu pensamento tendo como base o método fenomenológico, apresentando uma fenomenologia do feminino, denominada pela autora de 'filosofia da mulher'. Essa concepção põe em relevo a análise antropológica e filosófica em sintonia com uma teologia antropológica voltada para o desvelar da feminilidade.

A alma feminina, especialmente a humana, possui forças germinais de formas naturais, mas essas precisam ser modeladas "como a argila pela mão do artista ou como a rocha pela ação espontânea das intempéries, trata-se antes de uma raiz viva a formação que possui em si mesma a força natural germinativa na sua forma interna" (STEIN, 1999, p. 117). Pode-sedepreender, dessa leitura, que a alma é densa de essências originárias próprias da natureza humana que estabelece relações com o espaço natural. Deste modo, a alma feminina estabelece relações de maternidade com os elementos naturais que nos concebe, nos adormece e nos nutre. "Assim como todos os sonhos e todos os devaneios há um elemento material, há uma força natural, os devaneios e sonhos embalados proliferam" (BACHELARD, 1998, p. 120). 
Para Shiva (1988, p. 125), “o princípio feminino da natureza é simbolizado pelo dinamismo, atividade, criação, reprodução e regeneração". Shiva enfatiza que a mulher é conectada à natureza por meio de sua função metamorfoseante e reprodutiva da vida. $\mathrm{O}$ elo entre a natureza e o feminino emerge revigorando o amor materno ancestral pela natureza.

A alma feminina, no dizer de Stein, assemelha-se ao desenvolvimento de uma planta cujo crescimento e desenvolvimento orgânico exigem-se cooperações de condições externas e internas. Dessa forma, "é preciso acionar no interior da alma as forças que emergem ao intelecto e a vontade ao ânimo e ao contato daquilo que é capaz de motivar e preencher a alma internamente" (STEIN, 1999, p. 118). Há, com efeito, a necessidade de vivências ${ }^{66}$ nas relações externas e internas que é justamente a relação humana com a natureza, com o material. Assim se dá a relação essência-natureza, evidenciando o espelhamento estético ${ }^{67}$ da alma. De acordo com Stein (1999, p. 57), "onde as forças e relações essenciais são tão diferentes, deve haver também um tipo de alma diferente, apesar da natureza humana comum".

Ecoa na filosofia steiniana o pensamento que evoca a afetividade como o centro da alma feminina e, a identificação da mulher com a sua alma que é fundamental à natureza da própria mulher, a qual é chamada para desenvolver as sutilezas maternas, por exemplo: "o cuidar, zelar, conservar, alimentar e promover o crescimento" (STEIN, 1999, p. 58). Essa premissa assinala a essência materna da mulher em sua relação com a natureza. Ou seja, há algo de germinal na mulher enquanto essência humana que a relaciona com a Mãe-Terra, que é o aspecto da reprodução ou procriação de seres, ambas são geradoras de vida. Conforme Stearns (2007) há na agricultura uma relação simbólica entre a mulher e a terra. Bachelard (1998, p. 120) esclarece que,

Esse canto profundo é a voz maternal, a voz de nossa mãe [...] E esse algo de nós, de nossas lembranças inconscientes, é sempre e em toda parte resultado de nossos amores da infância, desses amores que a princípio se dirigiam apenas à

\footnotetext{
${ }^{66}$ Para a fenomenologia o termo 'vivência' não significa o conteúdo, mas a estrutura. $\mathrm{O}$ que interessa na percepção da coisa, por exemplo, como folha de papel, é a vivência da percepção. Temos uma universalidade de estrutura, mas diferentes conteúdos.

${ }^{67}$ Estética - não só aquela inscrita no espaço artístico convencional das obras classificadas e aceitas como arte, mas a capacidade de sentir, de perceber, os sentimentos que fazem parte da vida. Ver Morin (2005), a estética da alma.
} 
criatura, em primeiro lugar à criatura-abrigo, à criatura-nutrição que foi a mãe ou a ama de leite...

Pelo fato de a mulher possuir em sua humanidade a capacidade de gerar e nutrir no interior de seu corpo outro ser, ela é também, justamente por essa capacidade natural, mais afetiva e cuidadosa com o outro. Na melhor das hipóteses, a mãe tem com sua "cria" uma relação diferente daquela cultivada pelo pai. Daí a propensão natural da mulher a estar atenta aos problemas alheios. A empatia natural feminina se manifesta por meio da essência genitora de seu Ser, entendendo-se na relação com o outro humano ou com o meio natural. Em Stein (1999, p. 58) percebemos que "a essência feminina potencializada na singularidade da mulher compartilhar com a natureza uma experiência de opressão, e que possui experiências diferentes dos homens que as tornam capazes de falar de uma nova visão acerca".

Para Merleau Ponty (2006) a carne do mundo que conecta o ser humano à natureza não é espírito, nem matéria, mas sim um elemento, como o ar, a terra, o fogo e água, que dá origem a tudo. É através da carne do mundo que nos conectamos a natureza e nos comunicamos com o outro, e é justamente com essa noção de pertencimento à natureza que alcançamos o sentido da vida corpórea. $A$ natureza para o autor é tratada como um objeto enigmático, denominado pelo pensador como quiasma ${ }^{68}$, um objeto que não é inteiramente objeto, que não está inteiramente diante de nós. É o nosso solo, não é aquilo que está diante, mas o que nos sustenta. Nesse contexto, Stein (1999) vigora o pensamento de Merleau Ponty, haja vista que ambos florescem a ideia de que a natureza do Ser não é determinada pelo corpo (físico).

Stein (1999) aponta os perigos que a alma feminina enfrenta diante de forças externas que insistem em enquadrá-la por via de discursos e teorias rasas as quais são propensas a equívocos, na medida em que buscam assemelhar a essência feminina refletida na natureza extra-humana, com a essencialização da natureza da mulher. Este discurso se lastreou historicamente por diversas culturas, como o patriarcado, a ponto de fazer muitas mulheres enxergarem em sua natureza a fragilidade e a inferioridade, haja vista que no cenário capitalista se legitimou a máxima que "construir significa dinheiro, um mundo desenvolvido e uma sociedade

\footnotetext{
${ }^{68}$ Compreendida como uma lógica de inerência e entrelaçamento entre os fenômenos e realidades.
} 
desenvolvida tecnologicamente. Cultivar muitas vezes significa pobreza, um mundo ainda não inteiramente desenvolvido, e uma sociedade agrária ou pré-agrária" (BIGWOOD, 2007, p. 96).

Assim como Stein, Morin (2005) também demonstra preocupação com a simplificação do ser humano por meio dos bens materiais por ele produzidos. Para o pensador, o ser humano tem como natureza a complexidade, sendo, pois, denso de razão, criatividade, trabalho, arte, crença e sentimentos. Stein compreende o humano como um todo, mas toma em forma analítica o Ser individual, para mergulhar na diversidade de modos pelos quais a pessoa pode se relacionar, tendo em vista uma investigação da essência da pessoa humana.

Ela pensa o feminino para além da compreensão bio-psicofisiológico, concebe-o por via da natureza, pela límpida essência da mulher, longe de estereótipos fabricados e reducionistas que ocuparam os diversos campos do conhecimento. De acordo com essa autora,

Se, por um lado, encontramos homens de espírito que projetam no ser feminino um ideal luminoso, esperando que sua realização traga a cura para todos os males e perigos de nosso tempo, por outro, encontramos uma literatura que ainda mostra a mulher como demônio do abismo. É diante dessas formas de conceber a mulher que devemos nos perguntar "o que somos e o que devemos ser?. (STEIN, 1999, p. 105)

Essas assertivas remetem a percebermos a "essência da mulher na sua finalidade tripla: o desdobramento de sua humanidade, de sua feminidade, de sua individualidade" (STEIN, 1999, p. 140). A autora mostra o feminino como um ente com dimensões indissociáveis de interioridade e exterioridade, como lugar no ethos onde se revela a "essência da mulher na qual regula os atos humanos não como leis impostas do externo para o interno, mas como algo atuante dentro do ser humano como forma interna" (STEIN, 1999, p. 55-56).

Observa-se que o pensamento desenvolvido por Stein sobre a mulher é constituído de uma realidade humana própria, não apresentando apenas diferenças externas, biológicas, em relação ao homem. A mulher é detentora de um princípio inerente que a constitui como tal, um modo interior que compreende o ser permanente e singular em seu íntimo, mas nunca inferior ou superior ao outro de natureza comum. 
Essa ótica põe em relevo a ideia de que o desequilíbrio psicossocial, causado pela desarmonia entre as forças naturais do feminino e do masculino deve-se por estarmos vivendo numa cultura cuja masculinidade hegemônica foi exacerbada durante um longo período histórico. Como consequência, ainda nos tempos atuais a cultura do patriarcado destila violência simbólica ao inferiorizar os princípios da feminidade ligados à natureza. Em face dessa situação, Stein nos alerta para o fato de que é preciso ter cuidado para que, ao reluzir os valores da natureza feminina, não se cometam os mesmos desvios.

\section{A representação do 'eterno feminino' no imaginário amazônico}

A figura da mulher esteve sempre presente no interior das culturas, representando funções bem definidas e que procuram transmitir toda a força, protagonismo e também delicadeza que esta contém, tanto no meio social como também nas representações simbólicas e na cultura imaterial, tais como mitos e lendas.

Os mitos de origem nas culturas enfocam a importância do elemento feminino em seus ritos, assim o foi nas mitologias grega, egípcia e indígenas no Brasil, mais especificamente na Amazônia. As mulheres são seres arquétipos que sobressaem nos mitos como guardiãs das culturas, mas também como desencadeadoras de situações constrangedoras que atingem a humanidade, tais como Eva e Pandora.

Durand (1997), ao se debruçar sobre o estatuto gnóstico da $A$ Alma do Mundo, isto é, o conhecimento do mundo interior através do interior do mundo, considera que esse conhecimento é medido pela sabedoria feminina do saber, Sofia, como alma (anima) do mundo. Na mitologia grega o termo Theasofia, o significado de Thea/Tea é 'deusa', e Sofia/Sophia significa sabedoria ou saber. Trata-se do arquétipo do princípio feminino essencial: $O$ grande feminino é a sabedoria da Deusa, ou sabedoria do princípio divino feminino. A sabedoria sobre o caminho do despertar do poder superior, ou seja, o lado ou o polo feminino do divino, do sagrado, absoluto. São os saberes e práticas da verdadeira sabedoria e espiritualidade feminina.

A Theasofia se caracteriza como a sabedoria iniciática feminina. É a sabedoria das grandes sacerdotisas, xamãs, curadoras e 'senhoras' dos círculos de mulheres em todo o mundo, mas essa sabedoria é obliterada pelas tendências e 
necessidades mais paternalistas - sobre a essência do despertar do poder e consciência plena feminina ou do feminino transcendente.

No contexto amazônico destaca-se o próprio nome "Amazônia". Nome protagonizado por meio da história das mulheres icamiabas ${ }^{69}$, vistas como as lendárias amazonas ${ }^{70}$ pelo grupo de navegadores conquistadores espanhóis liderados pelo capitão Francisco de Orellana, que seguiu com seu grupo de homens expedicionários do Peru até o rio Amazonas no século XVI.

Também no mito do Jurupari encontramos ideias de que 'originalmente eram as mulheres quem possuíam as flautas', enquanto os homens se encarregavam do processamento da mandioca e outras tarefas femininas. Os mitos acrescentam outro detalhe importante: quando as mulheres tinham a posse das flautas, os homens menstruavam e, quando tiraram as flautas delas, fizeram com que as mulheres menstruassem. Em relação ao roubo das flautas sagradas pelas mulheres, Parokumu e Kehiri (1995, p. 102), esclarecem que,

As moças levaram o seu turi aceso e foram ao porto buscar o cipó. Ao chegar lá, procuraram debaixo da árvore nogemu e viram dois pedaços de paxiúba que brilhavam como ouro.

- Que beleza de paxiúba encontramos, disseram as moças, vamos levá-las. Mas os dois pedaços de paxiúba fugiram delas à medida que se aproximavam. Todavia, as duas conseguiram agarrá-las. Com as paxiúbas nas mãos, se perguntavam para que poderiam servir. [...] Por fim, chegou o peixe wayusoamu, o aracu de cabeça vermelha, que ensinou às moças como tocar as paxiúbas. Antes disso, elas haviam enfiado as paxiúbas na própria vagina, procurando experimentar para que poderia servir. O peixe pegou os pedaços de paxiúba e começou a soprá-los. Aí mesmo, eles começaram a tocar. Então, agarrando-se neles, as duas moças disseram: - Agora descobrimos a serventia deles, vamos tocar nós mesmas. E assim fizeram.

Esses mitos, e os rituais que os dramatizam, podem ser entendidos como um discurso complexo e ambíguo sobre os respectivos poderes e capacidades de homens e mulheres, tal como aquele que se refere aos poderes xamânicos femininos. Isso implica que os órgãos reprodutivos e as capacidades reprodutivas complementares de homens e mulheres, isto é, as suas "flautas", são

\footnotetext{
${ }^{69}$ Icamiabas' ou iacamiabas (significa "peito partido") é a designação genérica dada a índias que teriam formado uma tribo de mulheres guerreira que não aceitavam a presença masculina.

${ }^{70}$ Nome dado às mulheres guerreiras da Antiguidade que habitavam a Ásia Menor e cuja existência alguns historiadores consideravam um mito.
} 
simultaneamente idênticas e opostas, iguais e desiguais, invertidas e equivalentes. Como sugere Loureiro (2000, p. 195), "são inúmeros os mitos que povoam as encantarias amazônicas". A representação da natureza amazônica é como a grande Deusa Mãe, ente feminino verde e fluido que habita um labirinto de águas misteriosas. As variadas imagens arquetípicas que metaforizam essa grande Mãe Natureza mesclam a mitologia clássica greco-latina com os mitos amazônicos para recriar por meio da fórmula mágica do imaginário da floresta, o tempo das origens. Neste teor Krüger (2011, p. 277), considera que,

Como nos mitos, o fogo conduz ao fim do mundo e, nesse caso particular, significa o encerramento de uma estrutura social não acorde com os valores patriarcais. Como nas narrativas mitológicas, o mundo, porém, poderá ressurgir, havendo, portanto, que se tomar providências, dente elas, a de não permitir às mulheres, 0 acesso aos instrumentos musicais deixados por Jurupari. $O$ que equivaleria a lhes entregar 0 poder.

Note-se que mesmo com o visível e salutar simbolismo do elemento feminino nos mitos amazônicos a presença da mulher nessa cultura foi ofuscada para dar destaque à figura masculina, como vimos na descrição do mito do povo da Amazônia. Antes da ascensão do homem sobre a mulher a natureza feminina engendrava muitos mistérios e veneração às mulheres, pois a maternidade, o parto, a amamentação, a menstruação ainda tinham conotações mágicas. A Deusa-Mãe que foi inicialmente venerada pelos mistérios da concepção materna, passou a ser dotada de outras funções vitais como alimentação, fertilidade, poder criador e outros.

No âmbito da psicanálise Jung concebe o arquétipo da mãe como forma de mãe pessoal, avó, madrasta, sogra, enfermeira, governanta. Trata-se de um arquétipo que pode se efetivar em mães figurativas, como Maria Mãe de Deus, ou a mãe que se torna uma donzela novamente no mito de Deméter e Core ${ }^{71}$.

\footnotetext{
${ }^{71}$ De acordo com a mitologia grega,ore estava tranquila ao lado das ninfas e das divindades Ártemis e Atena, quando um dia seu tio Hades, que a desejava, a raptou com o auxílio de Zeus. O pai dos deuses, enquanto Core estava passeando pelo bosque fez aparecer um narciso às bordas de um abismo. No momento em que esta se aproxima da flor, a terra se abriu e ela foi conduzida para o submundo. Com o desaparecimento de Core, Deméter começou a vagar pelo mundo a procura de sua filha, passando nove dias e nove noites, sem comer, ou beber em busca da mesma. No décimo dia desde o desaparecimento da divindade silvestre, Deméter descobriu a verdade por Hélio (o que tudo vê) irritando-se com seus irmãos pelo feito, decidiu não mais voltar ao Olímpo. A divindade passou a vagar pelo mundo sob o aspecto de uma velha, até chegar à cidadede Elêusis. Devido a sua tristeza pela perda da filha, a terra passou por uma seca terrível, até que Zeus pediu a Hades que devolvesse a esta a filha. O deus dos infernos acatou o pedido do irmão, mas antes de permitir que Perséfone deixasse os seus
} 
Para Estés (1997) o princípio feminino como o arquétipo da Mulher tem o objetivo de resgatar a alma feminina ou a origem do feminino.Vejamos:

O arquétipo da Mulher pode ser expresso em outros termos igualmente apropriados. Pode-se chamar essa poderosa natureza psicológica de natureza instintiva, mas a Mulher é a força que está por trás dela. (...).

$\mathrm{Na}$ psicanálise e a partir de perspectivas diversas, ela seria chamada de id, de self, de natureza medial. Na biologia, ela seria chamada de natureza típica ou fundamental(ESTÉS,1997, p. 21-22)

O aspecto positivo do arquétipo mãe é o amor maternal tão celebrado na arte e na poesia, com o qual nos deparamos por primeiro no mundo. Mas, ele pode ter significado negativo, a mãe amorosa ou a terrível mãe ou deusa do destino. Neste sentido, Jung (1999) considerava a mãe o arquétipo mais importante, porque parecia conter uma dualidade de sentido.

No olhar de Paredes (1921), a representação do eterno feminino entre os povos andinos é emergida pela figura da Pachamama ${ }^{72}$. Essa figura materna referese ao tempo, ao tempo que cura as maiores dores, aquele também que extingue as alegrías mais intensas; ao tempo que distribui as estações, fecunda a terra, sua companheira; dá e absorve a vida dos seres no universo. Pacha significa originariamente "tempo", na língua kolla ${ }^{73}$; só com o transcurso dos anos - as adulterações da língua e o predomínio de outras raças - pôde confundir-se com a terra e fazer com que a esta e não àquele se rendesse preferente culto. Pachamama, segundo o conceito que tem entre os índios, poderia ser traduzido no sentido de terra grande, diretora e sustentadora da vida. A terra, como geradora da vida, será, então, assumida, como um símbolo de fecundidade. Conforme Paredes (1921, p.28),

Entender as situações variadas vividas pelo homem, fazê-lo compreender o mundo em que vive, reconhecer a realidade que se manifesta, relacionar a vida com a criação dos deuses e todas as coisas, tudo isso está conservado nos mitos. E o

domínios a fez comer uma semente de romã, aqueles que comessem qualquer coisa no mundo dos mortos não poderiam voltar ao convívio dos vivos. Finalmente, os deuses chegaram a um consenso, a filha de Deméter passaria quatro meses com o esposo e o restante do ano com sua mãe.

${ }^{72}$ Pachamama é conhecida também como a Mãe Terra. Ela representa a Deusa maior nas culturas andinas, capaz de mudar todo o sentido na vida de muitas pessoas, trazendo prosperidade, sustento e boa energia.

${ }^{73}$ Os kollas são um povo indígena descendente dos povos que formaram o império Inca. São originários do norte da Argentina, província de Jujuy, próximo à fronteira com a Bolívia. 
homem moderno necessita dessa forma de imaginação, pois o que acontece no mundo atual é que ele costuma rejeitar qualquer mistificação, não aceita facilmente um modelo de humanidade fora da condição humana tal como ela é.

Camargo (2006) é um critico ao termo Pachamama segundo a visão dos indígenas Kollas. De acordo com este autor o termo "mama" empregada apenas a uma mãe indefinida, e "pacha" somente ao vago binômio "tempo-espaço" reduz a Pachamama à mera encarnação feminina do tempo e do espaço, assumindo uma caracterização vaga e simplista, minimizando de toda sua complexidade e sutileza.

Observe-se que a cultura da floresta apresenta a figura feminina diante de forças duais e igualmente importantes: a cósmica, que provem do céu, e a telúrica, associada com a terra ligada espiritualmente a ancestral Pachamama ou Mãe-Terra. Ambas as forças convergem para o processo de geração da vida, geram toda forma de existência, pressupondo que tanto o orgânico quanto o inorgânico tem vida e espírito. Ademais, deve-se perceber que, a essência feminina busca atribuir aos seres vivos e até mesmo a seres inanimados, um lugar que se situa ao lado da falta, que está sempre receptiva a ser preenchida pelo desejo do outro. Há, então, um princípio na natureza que feminiza os seres assexuados, como por exemplo, uma planta. Essa essência se caracteriza principalmente por meio da receptividade atribuída à essência feminina, uma vez que sua essência se encontra mais aceptiva ao contato com o Divino. Stein (1999, p.138), discute esse tema elucidando que "toda mulher tem aptidões e dons individuais que a faz aspirar por uma vocação especial, além da feminina em geral". Assim sendo, observa-se que a pureza e a candura presente nas mulheres às aproximam do sagrado, de modo a thes assegurar um papel importante: o papel de semblante, a face feminina da natureza.

Ecoa a ideia de um eterno feminino, uma face do feminino presente na luminosidade das culturas indígenas que apresentam as mulheres como ancestralidades e sujeitos centrais na preservação do meio ambiente (TORRES, 2012). Conforme atesta Shiva (1992, p. 92), as mulheres são as que, de modo geral, "constituem a maior fonte de criatividade, elemento essencial para gerar mudança em respeito à natureza". De acordo com Da Silva (2013, p. 133) "o resgate do feminino com a Pachamama permite às mulheres acessarem seu lugar na história desses povos". É por meio da celebração do feminino que se alcança o contato com o natural, com a força produtiva sem destruição, a construção com equilíbrio. 
Estés (1997) constrói uma fenomenologia do feminino e sua representação essencial é a água, a qual, assim como a mulher, é geradora. A natureza é considerada a mãe, "La Madre Grande, a Grande Mulher" (ESTÉS, 1997, p. 380) cujas águas não só correm nas valas e leitos do rio, mas também se derramam de dentro do corpo das próprias mulheres quando seus filhos nascem. O rio simboliza uma das formas de generosidade feminina quando ele está vivo ${ }^{74}$ e flui, gerando e alimentando vidas. Assim como o feminino, a água é inclusiva, flexível, um ser de inter-relações por natureza. Por isso, ela é reconhecida como persistente, amorosa, complementar e receptiva.

Eisler (2007) busca uma explicação no argumento de que há evidências da divinização da fêmea, posto que a natureza biológica da mulher está ligada ao parto e à sustentação dos filhos pela maternidade. Para a autora, existe uma associação muito forte do princípio feminino com as águas, pois a mulher assim como a água ao se recriar na interação e na troca, desperta paixões, é excitante e faz a vida entrar em ebulição. Em seus remansos, as águas geram tranquilidade e serenidade. É essencialmente manutenção da vida; o vigor e a persistência são qualidades aquáticas do feminino.

Para Bachelard (1993, p.27), "é preciso chegar a uma fenomenologia da imaginação. [...] que abre as portas do conhecimento da alma". O autor sublinha a anima como um estado feminino e sublime da relação do Ser com o universo, que desperta emoções profundas através de uma psicanálise das imagens da água. As águas quando são claras, correntes, primaveris nos remetem ao nascimento, amor, pureza, equilíbrio do dia e noite, à vida.

Essa perspectiva Bachelariana reflete a sensibilidade mística da feminidade presente na percepção da natureza, na gestação da terra-fêmea ${ }^{75}$, na liquidez viscosa dos conteúdos conformados por seus continentes, enfim, na homologia das imagens místicas que constelam sob o arquétipo da água. Muitas são as imagens da água, não apenas vida e morte, o autor apresenta a água como maternal e feminina. Para ele, o sentimento que temos em relação à natureza é o de um filho para com a mãe e vê como um dos maiores símbolos maternos, o rio.

\footnotetext{
${ }^{74}$ Sobre a análise filosófica do "estar no mundo", estar no mundo é estar vivo, é o ser que está em movimento e em pleno metamorfoseamento.VerIngold(2005).

${ }^{75}$ Ver Paes Loureiro, 2000.
} 
Se o sentimento pela natureza é tão duradouro em determinadas culturas, como as dos povos indígenas da Amazônia, esse sentimento está na origem de todos os sentimentos. Em Bachelard (1989), todas as formas de amor recebem um componente de amor por sua mãe. É neste sentimento de gênese que está a preocupação ecológica do homem com a natureza e a atribuição desta como mãe, uma figura feminina. A Terra, de onde toda a vida brota e dá alimento aos seres vivos pode ser muito bem entendida como uma figura feminina, necessitando, pois, de uma percepção fenomenológica para explicar os elementos de assimilação com a figura materna.

\section{Considerações finais}

Este estudo concentrou-se numa discussão acerca da alma feminina e sua manifestação fenomênica, tendo por base as teorias de Edith Stein e Gaston Bachelard, em debate com outros teóricos, estabelecendo uma aproximação da alma feminina com a natureza, especialmente a terra e água. Discutimos também o feminino presente no universo ancestral dos povos da Amazônia envolvendo a natureza, a floresta, os rios e sua relação primeira com a terra e que até hoje repercute no imaginário dos povos da floresta.

Ademais, aqui reside a ideia de natureza enquanto ser feminino associada à mulher e suas características fundamentais como a beleza, o corpo, os seios, a maternidade que são únicas. É preciso repensar o papel da mulher nas múltiplas expressões culturais compreendendo o ser feminino associando ao sagrado ou o eterno feminino. Precisamos compreender a Amazônia, cuja natureza engendra uma essência feminina. Pode ser percebido nas relações de ancestralidade que os povos originários têm com esta natureza exuberante, que é um vasto campo de estudo que necessita de uma discussão mais profunda a partir de uma fenomenologia da natureza.

\section{Referências}

BACHELARD, G. A água e os sonhos: ensaio sobre a imaginação da matéria. São Paulo: Martins Fontes, 1989. 
A poética do espaço. São Paulo: Martins Fontes, 1993.

BIGWOOD, C. Logos ofOur Eco in theFeminine: An approach through Heidegger, Irigarayand Merleau-Ponty. In: (orgs.) HAMRICK, William S.; CATALDI, Suzanne L. Merleau-Ponty and Environmental Philosophy: DwellingontheLandscapesofThought. Albany: StateUniversityof New York Press. p. 93 - 116, 2007.

CAMARGO, A. J. C. J. Bolívia: a criação de um novo país a ascensão do poder político autóctone das civilizações pré-Colombianas a Evo Morales. Brasília: Ministério das Relações Exteriores, 2006.

DA SILVA, A. A construção de gênero nas Relações Internacionais: Direitos Humanos das Mulheres e a necessidade de instrumentos eficazes à sua consolidação. [Dissertação]. Florianópolis: Universidade Federal de SC, 2013.

DURAND, Gilbert. As estruturas antropológicas do imaginário. Tradução de Hélder Godinho.São Paulo: Martins Fontes, 1997.

ESTÉS, C. P. Mulheres que Correm com Lobos: mitos e histórias do arquétipo da mulher selvagem. Rio de Janeiro: Rocco, 1997.

HUANACUNI, Fernando.Cosmovisión andina:Tierra y territorio autodeterminación de lospueblos. In.Sariri-Caminante de los Andes, junio 2007.

INGOLD, Tim. Estar vivo: ensaios sobre movimento, conhecimento e descrição. São Paulo: Vozes, 2015.

JUNG, E. Animus e Anima. 12ª edição, São Paulo: Cultrix, 1999.

LOUREIRO, Paes. Obras reunidas. São Paulo: Escrituras Editora, 2000.

KRUGER, Marcos Frederico. Amazônia: mito e literatura. 3. ed. Manaus: Editora Valer, 2011.

MERLEAU-PONTY, M. A Natureza: curso do Collège de France. São Paulo: Martins, 2006.

MORIN, Edgar. Introdução ao pensamento complexo. Porto Alegre: Editora Sulina, 2005.

MORIN, Edgar. $O$ admirável estético e ético como ideal supremo da vida humana. In: SILVA, Jorge Anthonio (org). Encontros estéticos. Coletânea de textos do Evento Encontros Estéticos no Conjunto Cultural da Caixa Econômica. São Paulo: janeiro a junho de 2005.

PAREDES, M. RIGOBERTO "Anotaciones Bibliográficas.Las obras de donHoracio H. Urteaga": En "Boletín de laSociedad Geográfica de La Paz" La Paz-Bolivia. Sep. 1921.

PAROKUMU, UmúsinPanlõn, KENHÍRI, Tolamãn. Antes o mundo não existia - $\boldsymbol{A}$ mitologia heróica dos índios Desâna. São Paulo: Cultura. 1980.

SHIVA, Vandana. "A semente e a Terra: mulheres, ecologia e biotecnologia"In: OLIVEIRA, Rosiska; CORRAL, Taís (Org.). Terra Feminina. REDEH, 1992. 
Kali for Women, 1988.

StayingAlive: Women, EcologyandSurvival in India. New Delhi:

STEIN, Edith. A Mulher: Sua missão segundo a natureza e a graça. Tradução de Alfred J. Keller. Bauru/SP: EDUSC, 1999.

TORRES, Iraildes Caldas. Constituição etnográfica da comunidade Nossa Senhora de Nazaré do Barro Alto. In: TORRES, Iraildes Caldas. (Org.). O Ethos das mulheres da floresta. Manaus: Editora Valer/ FAPEAM, 2012. 